Mirai. Estudios Japoneses

ISSN-e: 1988-2378

\title{
Imágenes para el recuerdo. Japón en las fotografías de Oleguer Junyent del Instituto Amatller de Arte Hispánico
}

\author{
Carolina Plou Anadón ${ }^{1}$
}

Resumen: La fascinación que ejerció Japón en Occidente a partir de su apertura en el siglo XIX es más que patente, y dio lugar a numerosos testimonios artísticos durante el japonismo. Desde la apertura del país en 1868, el conocimiento de Japón en Occidente se incrementó a través del comercio. Con el avance del periodo Meiji creció también el número de visitantes que se desplazaban al País del Sol Naciente en el contexto de viajes de placer.

Dentro del ámbito de la fotografía, este interés por Japón se tradujo en una codificación de las imágenes producidas dentro de un contexto comercial. Estas fotografías souvenir constituyeron un negocio muy importante, pero también un medio de difusión de la imagen japonesa.

Frente a este fenómeno, que supone la tónica habitual en la fotografía del periodo Meiji, queremos presentar el trabajo de un artista español, Oleguer Junyent, quien visitó Japón en torno a 1908, en el contexto de un viaje alrededor de mundo. A través de las fotografías que realizó, analizaremos la manera en que mira como occidental sobre Japón aportando un punto de vista particular y alternativo a los estándares comerciales.

Para ello, nos apoyaremos en la obra Roda el món i torna al Born, libro de viajes profusamente ilustrado que Junyent publicó a su vuelta en 1910, si bien nuestro objeto de estudio serán las fotografías conservadas en el Instituto Amatller de Arte Hispánico, que se integran dentro del corpus fotográfico del Archivo Adolfo Mas.

Palabras clave: Oleguer Junyent; Japón; fotografía; viaje.

\section{[en] Remembrance images: Japan in Oleguer Junyent's photography collection at Amatller Hispanic Art Institute}

\begin{abstract}
From the moment of the opening of Japan in the $19^{\text {th }}$ century, the West experienced an enormous fascination with this country, an attraction that generated many artistic testimonies during the time of Japonisme. From 1868, the knowledge the West had of Japan increased through commerce and, later on in the Meiji era, through visitors who, in increasing numbers, travelled to the Land of the Rising Sun as a leisure destination.

Regarding photography, the interest on Japan materialized itself in the commercialization of sets of pictures with codified iconographies. These souvenir photographs turned into a thriving business, but at the same time they became a means by which the image of Japan was disseminated.

In contrast to this phenomenon, most common in the Meiji period, this paper addresses the photographic work by Oleguer Junyent, a Spanish artist who visited Japan around 1908 as part of a world tour. Through his photographs, we will study how this Western figure established a different set of parameters in his observation of Japan, offering a particular point of view alternative to commercial standards. Although the object of our study are the photographs kept in the Amatller Hispanic Art Institute, which are part of the photography collection of the Adolfo Mas Archive, we will also support our investigation on the work Roda el món i torna al Born, the travel book Junyent published after his return in 1910, which is profusely illustrated.
\end{abstract}

Keywords: Oleguer Junyent, Japan, photography, travel

Universidad de Zaragoza.

carolinaplou@gmail.com 
Cómo citar: Plou Anadón, C. (2017). Imágenes para el recuerdo. Japón en las fotografías de Oleguer Junyent del Instituto Amatller de Arte Hispánico (2017), en Mirai. Estudios Japoneses 1, 2017, 217-224.

Las fotografías que suponen el objeto de estudio del presente trabajo conforman una pequeña colección de treinta y siete imágenes sobre Japón. Fueron tomadas por el artista barcelonés Oleguer Junyent (1876-1956) durante su estancia en el País del Sol Naciente, como parte de un viaje alrededor del mundo que realizó entre 1908 y $1909^{2}$. Se trata de una serie de instantáneas tomadas con la finalidad de servir de recuerdo, sin excesivas pretensiones artísticas (aunque en algún caso pueden intuirse ciertas nociones). No obstante, posteriormente experimentarían otros usos diferentes y complementarios a su función inicial.

En la actualidad, dichas fotografías se custodian en el Instituto Amatller de Arte Hispánico de Barcelona, como parte de su extensa fototeca. Esta institución, de carácter privado, fue fundada en 1941 por José Gudiol Ricart, bajo el mecenazgo de Teresa Amatller, hija del industrial chocolatero y fotógrafo Antoni Amatller, con el objetivo de custodiar tanto las colecciones familiares como otros fondos de diversas procedencias. Tiene como sede la Casa Amatller, edificio levantado por el arquitecto modernista Puig i Cadafalch en el Paseo de Gracia.

Entre los numerosos fondos fotográficos que custodia el Instituto Amatller de Arte Hispánico se encuentra el Archivo Mas, un archivo fotográfico fundado por el fotógrafo Adolfo Mas Ginestà en 1900, y que cuenta con unos trescientos cincuenta mil negativos, en su mayoría dedicados al Modernismo y a representaciones artísticas de toda clase. Este archivo, que comprende en su haber las fotografías de Oleguer Junyent, fue cedido por Pelai Mas Castañeda al Instituto Amatller en el año de su fundación.

Con respecto a cómo llegaron a integrarse en el Archivo Mas las fotografías de Oleguer Junyent no se conserva documentación ni información que precise el momento, la causa o las condiciones de esta integración. No obstante, la hipótesis que puede considerarse como oficial es que los negativos fuesen cedidos por Junyent debido a la amistad que presumiblemente unía a ambos personajes, figuras de gran importancia en la sociedad burguesa de la Barcelona de principios del siglo XX con intereses comunes en el campo de la fotografía.

\footnotetext{
Oleguer Junynet comenzó su carrera como escenógrafo, formado en los talleres de Fèlix Urgellès y de Francesc Soler i Rovirosa. En su juventud, se manifestaría una gran inquietud viajera, como atestiguan sus desplazamientos a Alemania, Italia, Francia y por la Península Ibérica, en los cuales invertía la dotación de algunos trabajos o galardones recibidos. Fruto de esta pasión por conocer otras culturas, en 1908 emprendió un viaje, acompañado de su amigo Mariano Recolons, en el que ambos dieron la vuelta al mundo, recorriendo Egipto, la India, Ceilán, bordeando Australia, Filipinas, las costas de China, Corea, Japón, Canadá y Estados Unidos a lo largo de once meses. Tras el viaje, Junyent realizó en Barcelona una exposición con los dibujos que había realizado durante el mismo, incluyendo también material de apoyo (guías de viaje, documentación sobre hoteles y trenes, etc.). Posteriormente, viviría unos años dorados como escenógrafo, profesión de la que se retiró en 1924 para dedicarse a la pintura y a actividades sociales. Tras la Guerra Civil, prácticamente abandonó toda actividad pública, y finalmente, tras su muerte en 1956, cayó en el olvido, eclipsado por la extensa nómina de personajes coetáneos que alcanzaron una mayor presencia en la memoria colectiva. Se realizaron varios intentos de recuperación de su figura, comenzando por una exposición retrospectiva en 1961, si bien estos intentos quedaron en hitos aislados y no vieron continuidad en un estudio pormenorizado del personaje. Miralles, Francesc (1994): Oleguer Junyent. Barcelona: Cetir Centre Mèdic; Plou AnAdón, Carolina (2015): "Roda el món i torna al Born. Aproximación al viaje y a la obra de Oleguer Junyent”. En III Congreso Virtual sobre Historia de la Caminería. Jaén, 15 al 30 de septiembre de 2015, Jaén, Revista Códice, 2015. Disponible en: http://www.revistacodice.es/publi_virtuales/III_C_H_CAMINERIA/comunicaciones/12_Roda_1_mon_i_torna_al_Born.pdf [Consulta:29-05-2017].
} 
Todas las fotografías japonesas presentan como característica común el revelado sobre una tarjeta postal, que puede inducir a error sobre su finalidad y esencia. No se trata en ningún caso de postales circuladas, o de diseños concebidos para su distribución en formato postal, sino que este detalle responde a unas necesidades prácticas, presumiblemente de Adolfo Mas, realizando el revelado de los negativos en el material más económico del que dispusiera. Cabe suponer, de manera razonable, que estos revelados perteneciesen a algún tipo de catálogo de muestras dentro del Archivo Mas, que permitiese la selección de fotografías con mayor comodidad. En este sentido, merece la pena adelantar que algunas de estas fotografías fueron reproducidas en la Enciclopedia Gráfica. El Japón, que Jideko Sellés publicó en 1929 en la revista mensual Enciclopedia Gráfica de la Editorial Cervantes ${ }^{3}$.

Cada una de estas tarjetas postales incluye el revelado de la fotografía, en un formato cercano al cuadrangular (con unas dimensiones aproximadas de 10,5 x $9 \mathrm{~cm}$ ), quedando en la zona derecha de la postal una franja de unos 3,5 centímetros despejada, en la que se ha incluido, manualmente, una breve descripción geográfica, consistente en país, lugar y, en ocasiones, una referencia descriptiva, así como un número de inventario. Existen dos tipos de apuntes diferentes: unos realizados a lápiz, en seis de las treinta y siete, que describen el objeto fotografiado («font d'un temple», «carrer», «pont sagrat»), y otros, con tinta de pluma o bolígrafo, que localizan e identifican la fotografía. En todos los casos, la caligrafía pertenece, inequívocamente, o bien a la integración de las fotografías en el Archivo Mas, o a su reagrupación dentro del Instituto Amatller. El hecho de que alguna de las notas a lápiz haya sido tachada con tinta hace suponer la posibilidad de que las notas a lápiz pertenecieran a la primera etapa, al Archivo Mas, y las notas a tinta se hubiesen añadido con la incorporación del fondo al Instituto Amatller. No obstante, a falta de documentación que lo confirme, únicamente podemos plantear esta posibilidad como hipotética.

Las treinta y siete fotografías se reparten, atendiendo al lugar en el que fueron tomadas, de la siguiente manera: dieciséis pertenecen a Kioto, nueve a Miyanoshita, ocho al Santuario de Nikko y cuatro al Santuario de Itsukushima. A nivel temático pueden clasificarse entre fotografía de monumentos, retratos, individuales o colectivos, y escenas cotidianas. En cierto sentido, pueden trazarse paralelismos entre estas imágenes y las producidas dentro del fenómeno comercial de la fotografía Meiji. Coinciden los temas, coinciden los lugares fotografiados, pero difiere el tratamiento.

Las fotografías de Oleguer Junyent son más libres, ajenas a la esclavitud iconográfica impuesta por la búsqueda desenfrenada de satisfacer un gusto colectivo occidental que caracteriza a la fotografía Meiji. Frente a ello, Junyent sitúa la cámara donde quiere, dispara cuando considera oportuno, y encuentra en el resultado como única respuesta la satisfacción de su propio gusto.

La realización de estas fotografías evidencia una gran espontaneidad. Aunque la fotografía suponga, de manera inherente, la manipulación de la realidad para adecuarla a unas intenciones, a unos fines o a unos ideales, en este conjunto de imágenes la intervención de Junyent se reduce al mínimo: la colocación de la cámara. En el caso de los retratos y escenas cotidianas esta intervención puede ser algo mayor, pero no se realiza una disposición estratégica y cuidadosa de los elementos para explotar todo el potencial plástico y evocador de la composición, sino que se limita a una serie de indicaciones cotidianas y coloquiales para nosotros: "ponte ahí", "sonríe",

Sellés Ogino, Jideko (1929): Enciclopedia Gráfica El Japón. Barcelona: Editorial Cervantes. 
"mira a cámara", generaciones que ya hemos crecido percibiendo la fotografía como algo propio ${ }^{4}$.

Otro rasgo a destacar de estas fotografías es su fuerte contraste lumínico, con zonas de sombra muy marcadas y, en algunos casos, excesivo. Este efecto es fruto del amateurismo de las imágenes, ya que en ninguna de las fotografías en las que se presenta esta circunstancia se aprecia un uso intencionado de la sombra. En este sentido, los desequilibrios lumínicos responden a las circunstancias en las que se han tomado las fotografías, todas ellas en exteriores que condicionaban fuertemente las posibilidades técnicas de la cámara.

Resulta interesante también hacer un análisis más pormenorizado, atendiendo a las fotografías de manera particular. Aunque en esta ocasión contamos con una limitación espacial que impide realizar un análisis individual de las treinta y siete imágenes, sí podemos adentrarnos un poco más profundamente en las distintas representaciones y en la imagen de Japón que transmiten.

No obstante, antes de profundizar en las fotografías, cabe destacar que esta colección no responde con exactitud a un reflejo del viaje. La ruta realizada por Oleguer Junyent y Mariano Recolons en Japón difiere bastante de la usual, como el propio Junyent reconoce en el libro de memorias sobre el viaje, Roda el món i torna al $B o r n^{5}$, ya que ambos llegan al País del Sol Naciente a través de Miyajima, una visita inicialmente no contemplada que surgió de la recomendación de otro viajero, y a partir de ahí, se desplazan de oeste a este. Si bien todas las regiones que comprende esta colección fueron visitadas por Junyent, no se conservan en este fondo fotografías pertenecientes a otros lugares que también visitaron. Por lo tanto, no puede considerarse que se trate de un muestrario representativo de la etapa japonesa del viaje.

No obstante, sí que presentan cierta representatividad respecto al impacto que le causaron los lugares visitados. A Kioto, como adelantábamos, pertenecen dieciséis fotografías. Es natural que el corpus más numeroso corresponda con una de las urbes más importantes del país, percibida además como centro de la cultura tradicional nipona, con el aliciente que aquello despertaba — todavía hoy despierta — para la curiosidad occidental, si bien las fotografías de Junyent mantienen esa impronta personal que, como ya hemos desarrollado anteriormente, caracteriza a estas fotografías.

Kioto fue, sin duda, uno de los enclaves que mayor impacto causó en el artista. Si bien en Roda el món i torna al Born lo que hace volar su pluma fue la gran cantidad y variedad de espectáculos teatrales de todo tipo a los que tuvo ocasión de acudir, y sobre los que pudo realizar reflexiones, tanto teóricas como gráficas a través de múltiples esbozos y dibujos. A nivel fotográfico Kioto aglutina la verdadera esencia nipona a ojos de Junyent. Representa, cámara mediante, numerosos espacios religiosos, pero no lo hace desde la perspectiva habitual que ensalza la arquitectura

4 Evidentemente, es prácticamente imposible conocer con exactitud la intervención exacta del autor en la toma de estas fotografías, si bien su naturalidad permite ver claramente cómo se trata de intervenciones nimias. No es descabellado aventurar algunos de los comentarios que posiblemente precediesen a la toma de la fotografía, precisamente, porque en esta cercanía que nosotros tenemos con el medio fotográfico se encuentra, de manera implícita, la capacidad de leer las reacciones a las que responde la imagen. A diferencia de la fotografía comercial producida durante el Periodo Meiji (1868-1912), donde todos los aspectos de cada fotografía están calculados con sumo cuidado para ofrecer una imagen que satisfaga al espectador occidental, plagada de elementos artísticos y culturales tradicionales, Junyent pretende solamente dejar testimonio fotográfico y visual de su experiencia, atesorar el instante de manera gráfica para evitar que pueda borrarse de su memoria, y esa sencillez se transmite a través de la imagen.

5 Junyent I SAns, Oleguer (1910): Roda'l món i torna al Born: Barcelona, Ilustració Catalana, p. 261. 
como magistral, como exótica o como una combinación de ambos rasgos, sino que lo hace mostrando la vida cotidiana en torno al templo. Para ello, se vale de encuadres que permitan percibir el flujo de gente ${ }^{6}$, aprovecha situaciones en las que la vitalidad del lugar es especialmente notable ${ }^{7}$, retrata a espontáneos y acompañantes o realiza vistas atípicas, en las que se muestran rincones del templo en relación con el espectador-fotógrafo en lugar de supeditar las vistas a la exhibición de la propia magnificencia de la arquitectura.

Las fotografías sobre Kioto no se ciñen estrictamente a la arquitectura religiosa de la ciudad, aunque la presencia de templos entre estas imágenes es destacada: doce de las dieciséis fotografías. También aparece una fotografía de una calle ${ }^{8}$, de un puente en construcción ${ }^{9}$ y dos pertenecientes a unos rápidos. En estas dos fotografías puede verse, en primera persona, el descenso por los rápidos de Katsuragawa, junto a la localidad de Hozu. Quizás sean estas las fotografías que mejor entroncan con el concepto moderno de fotografía turística amateur, ya que inmortalizan la experiencia del descenso en barca desde la propia barca, sirviendo por un lado de retrato cotidiano de los barqueros que conducen las pequeñas embarcaciones, y por otro, de instante fijado tanto en el recuerdo inmaterial como en la memoria física de imágenes producidas durante el viaje. Junyent no busca la representación de la belleza de la naturaleza en un valle en el que esta característica es indisoluble de su esencia, sino que se centra en la experiencia de la navegación. Yendo todavía un paso más allá, no busca mostrar lo agitado del descenso por estas aguas bravas, sino que pone el foco en la concentración y serenidad de aquellos que están conduciendo a buen puerto la aventura.

La segunda localidad en número de fotografías es Miyanoshita. A pesar de su número (nueve fotografías), en este caso apenas aportan información o un tratamiento particular. Si las consideramos de manera aislada, se trata de imágenes de turista: un

6 Dentro de este lote de fotografías, hay dos tomadas exactamente desde el mismo punto, en momentos distintos, y con una separación entre ambas, ya que el flujo de gente que puede verse es completamente diferente. Se trata de dos imágenes del espacio abierto de un templo, junto a la fuente de abluciones. En las distintas fotografías, tomadas desde el mismo punto, aparecen un grupo de niñas jugando o un grupo de varios hombres adultos, vestidos a la japonesa, pero tocados con sombreros occidentales, que abren el paso a una comitiva de soldados uniformados. Desde ese mismo punto de vista, Junyent realizó una acuarela mostrando el tránsito en torno a la fuente, en la que la gente que aparece se dispone de manera distinta a como ocurre en los ejemplos anteriormente citados, de manera que todo apunta a que se trata de una pintura realizada del natural y no sirviéndose de las fotografías como modelo. La suma de estos ejemplos hace pensar que ese emplazamiento concreto tuvo para Junyent un especial significado, pues este tipo de repeticiones no abundan en Roda al món i torna al Born ni en los testimonios que hasta ahora han podido hallarse de su viaje.

7 El mejor ejemplo de estas situaciones que Junyent aprovecha para mostrar la vitalidad de las arquitecturas religiosas es la fotografía que muestra la excursión que un colegio femenino realiza a un gran templo, en la que de manera totalmente secundaria, fragmentada y casi accesoria, puede verse la pagoda del recinto. En primer plano, recibiendo el peso protagónico de la escena, la comitiva de niñas que, en parejas y vestidas con kimono, miran curiosamente a su alrededor. Las alumnas de las diferentes clases se suceden en una hilera serpenteante, que sube por una senda hasta el nivel en el que se levanta la pagoda. Indudablemente, la pretensión de esta fotografía no es mostrar la disposición de los elementos arquitectónicos y naturales del templo, sino representar cómo, al igual que en Occidente, las escuelas japonesas también llevaban a sus alumnos a distintas excursiones para conocer mejor su entorno.

8 No se trata de una bulliciosa avenida llena de comercios y locales de ocio, sino más bien una pequeña vía, aparentemente de una zona residencial o de tránsito limitado, a pesar de lo cual deja ver la actividad y el movimiento de los vecinos.

9 De nuevo, a través de esta fotografía, Junyent vuelve a demostrar su interés por un Japón vivo y cotidiano. No (o no solo) presta atención a las grandes estructuras de la ingeniería nipona en su máximo esplendor y celebridad, sino que su preocupación se dirige hacia la creación de estas estructuras que cubren necesidades vitales. 
retrato del propio Junyent junto a una imagen de Buda tallada en una roca, algunos paisajes naturales, una fotografía de varios niños jugando y llevando a sus hermanos menores a cuestas (un rasgo llamativo de la cultura nipona que fue también muy representado en la fotografía Meiji), y varios retratos de mujer en los que la modelo no manifiesta ningún ademán de posar o querer participar activamente de la fotografía. Más bien, transmiten la impresión de ser peticiones transmitidas por Junyent a la mujer ${ }^{10}$ para enriquecer las fotografías de un merendero a la orilla del lago.

De las ocho fotografías atribuidas a Nikkō, una podría tratarse de Miyanoshita, ya que responde a un enclave similar a la fotografía de los niños anteriormente citada y también aparece en primer plano una muchacha con un bebé atado a la espalda. Tanto la anterior, ubicada en Miyanoshita, como esta, ubicada en Nikkō, acompañan el apunte geográfico con un interrogante, de modo que podrían pertenecer indistintamente a cualquiera de los dos sitios. No obstante, basándonos únicamente en las propias fotografías que integran esta colección, es más probable que se trate de Miyanoshita que de Nikkō.

Con las siete fotografías restantes no existe margen de error respecto a su procedencia. Cinco muestran inequívocamente distintos rincones del santuario, si bien en todos los casos lo hacen desde perspectivas que rompen con las imágenes tradicionales, casi canónicas, que se producían para uso comercial. En este sentido, resulta especialmente llamativo el caso del Shinkyō o puente sagrado, en el que la fotografía se ha tomado desde la orilla derecha, mientras que las fotografías comerciales solían representarlo indistintamente desde ambas orillas o desde el puente paralelo, buscando la máxima frontalidad para mostrar la construcción en todo su esplendor. Una sexta fotografía muestra un paisaje natural, un riachuelo discurriendo entre las montañas, si bien la calidad de la imagen no permite contemplar siquiera los detalles.

Finalmente, la última fotografía de Nikkō es un divertido retrato a caballo de Mariano Recolons. Jinete y montura aparecen de riguroso perfil, recortados contra el nevado paisaje invernal. El retrato, con un horizonte muy elevado, prácticamente desencuadra al personaje, si bien deja en la zona inferior un amplio margen en el que se recorta la silueta de Junyent, con los brazos doblados, realizando la fotografía. En el reverso de esta fotografía puede leerse, a lápiz, «En Mariano Recolons, excursió al Llach Chuzenji, props de Nikko». Se trata de la única fotografía con una indicación más detallada en el reverso, ya que en el resto únicamente figura la fecha («any 1908») y el mismo número de inventario que aparece también en el anverso.

Las cuatro fotografías de esta colección que restan por analizar pertenecen a Miyajima. Como se ha adelantado, en su libro Junyent explica que la visita a este santuario responde a la improvisación, motivada por la recomendación de un conocido durante el viaje hacia el archipiélago nipón ${ }^{11}$.

El santuario de Itsukushima era considerado, ya desde el Periodo Edo (16031868), uno de los enclaves más bellos de Japón. Tanto en el arte previo a 1868 como en la fotografía y en el arte producidos durante el Periodo Meiji, este santuario logró

10 Es posible que se tratase de dos mujeres diferentes, si bien la calidad de las fotografías no permite asegurarlo, en uno de los cuatro retratos femeninos la mujer lleva un kimono más oscuro. Sería extraño que perteneciesen a sesiones fotográficas diferentes, por las similitudes entre las imágenes, porque no se trata de un enclave con un atractivo especial que sugiriese la necesidad de volver para realizar nuevas fotografías, de modo que podría suponerse que se tratase de alguna acompañante, tal vez responsable del alojamiento, la esposa de un posible guía o alguna amistad labrada durante el viaje, si bien nuevamente en este terreno solamente nos cabe elucubrar.

11 Véase nota $n^{\circ} 4$. 
convertirse en una imagen icónica, que todavía en la actualidad se asocia de manera directa con Japón, gracias al gran torii o puerta sagrada que, situada frente al santuario, delimita el espacio sagrado del mismo. Partiendo de una tradición según la cual toda la isla era terreno divino y ningún mortal podía pisar su suelo, se edificó un templo, en la costa, en buena medida flotando sobre el agua del mar. Con el paso del tiempo, el lugar se popularizó como centro de peregrinación, y la imagen del gran torii que precedía la entrada al santuario adquirió merecida fama, por su espectacularidad. Desde entonces, lo habitual era representar el torii como principal protagonista, con el santuario de fondo o directamente, en imágenes que observaban la estructura desde el santuario, haciendo que se recortase sobre el horizonte. Tanto con la marea alta, momento en el que el torii parece emerger y flotar sobre las aguas, como con la marea baja, cuando puede llegar a atravesarse andando, el poder icónico de la estructura en rojo recortándose sobre los azules del cielo y el mar y los ocres del suelo marino, ofrecía un contraste atractivo que ejercía fascinación tanto entre los japoneses como, por supuesto, entre los extranjeros que visitaban el lugar o que lo conocían de manera indirecta.

Al contrario que la tónica habitual en la representación del santuario de Itsukushima, las fotografías de Junyent atienden por igual al complejo arquitectónico que al gran torii. Dos de las cuatro imágenes muestran distintos edificios y las escalinatas y empinadas calles que conducen de uno a otro, con la naturaleza rebosando tras y junto a las construcciones. Las otras dos fotografías sí tiene como protagonista al torii, pero no lo retratan como una gran estructura que irrumpe espectacularmente en mitad de un horizonte plano y aislado, sino más bien como un elemento más, integrado con el resto de elementos que conforman el espacio sagrado. En ambas fotografías, valiéndose de la perspectiva, establece un diálogo entre el gran torii y las linternas pétreas de distintos tamaños que se disponen por la playa. En cierto modo, estas dos fotografías parecen presentar cierta influencia de algunas vistas estereoscópicas que, popularizadas a partir de 1900, forzaban la perspectiva y recurrían a la integración de otros elementos para conseguir que el efecto tridimensional fuese realmente impactante $^{12}$. Si bien las similitudes formales y estilísticas podrían hacer sospechar de esta influencia, corroborada por la cronología, es excesivo pensar que Junyent estaba buscando explícitamente reproducir estas fotografías. Por el contrario, en consonancia con el afán rupturista con las iconografías preestablecidas por la fotografía Meiji, es probable que simplemente tratase de dar su visión personal y basada en su propia experiencia de este monumento icónico del arte japonés.

En definitiva, puede concluirse que este conjunto de treinta y siete fotografías responde a la visión personalísima de un artista cuyas inquietudes se dirigían hacia lo cotidiano. Mediante estas instantáneas, Junyent no pretendía adquirir influencias que revolucionasen su producción artística, sino que se dejaba llevar por las gentes que conocía en su viaje, admirando la belleza de la vida diaria de aquellas culturas que, tan alejadas de la suya propia, tenían en común sin embargo numerosas inclinaciones, y, más allá de lo puramente cultural, compartían un mismo tiempo. Que la

12 Un ejemplo de esta nueva forma de representar el torii de Miyajima puede encontrarse en una fotografía custodiada en el Museo Universidad de Navarra, procedente del antiguo Fondo Fotográfico Universidad de Navarra, que ya fue estudiado en su momento. Plou Anadón, Carolina (2013): La fotografia japonesa del periodo Meiji (1868-1912) y su presencia en España. La colección del Fondo Fotográfico de la Universidad de Navarra. Trabajo Fin de Máster dirigido por Elena Barlés Báguena / David Almazán Tomás. Facultad de Filosofía y Letras, Universidad de Zaragoza, Zaragoza. 
estética difiriera no impedía a Junyent aproximarse a la esencia detrás de las cosas, en algunos casos de manera acertada y en otros con una visión distorsionada por el paternalismo colonial de su época. En cualquier caso, estas fotografías evidencian ese interés y ese conocimiento profundo, esa reflexión sobre el entorno y ese deseo de mantener vivas las memorias de un viaje tan atípico como envidiable. 